Research Article

\title{
Cardioprotective Effect of Croton macrostachyus Stem Bark Extract and Solvent Fractions on Cyclophosphamide-Induced Cardiotoxicity in Rats
}

\author{
Muluken Altaye Ayza $\mathbb{D}^{1},{ }^{1}$ Rajkapoor Balasubramanian $\mathbb{D}^{2},{ }^{2}$ and Abera Hadgu Berhe $\mathbb{D}^{1}$ \\ ${ }^{1}$ Department of Pharmacology and Toxicology, School of Pharmacy, Mekelle University, Mekelle, Ethiopia \\ ${ }^{2}$ Department of Pharmacology, JKK Nattraja College of Pharmacy, Komarapalayam-638 183, Namakkal Dist, Tamilnadu, India
}

Correspondence should be addressed to Muluken Altaye Ayza; mulealto1@gmail.com

Received 14 December 2019; Revised 4 February 2020; Accepted 9 March 2020; Published 31 March 2020

Academic Editor: Arpita Basu

Copyright (C) 2020 Muluken Altaye Ayza et al. This is an open access article distributed under the Creative Commons Attribution License, which permits unrestricted use, distribution, and reproduction in any medium, provided the original work is properly cited.

\begin{abstract}
Context. Croton macrostachyus Hochst. ex Delile (Euphorbiaceae) has been used in traditional medicine to manage heart failure and other heart diseases in Ethiopia. Objective. To evaluate the antioxidant and cardioprotective activities of stem bark extract and solvent fractions of Croton macrostachyus on cyclophosphamide-induced cardiotoxicity in rats. Materials and Methods. DPPH free radical scavenging assay method was used to determine antioxidant activity whereas Sprague-Dawley rats were used to evaluate the cardioprotective activity. Except for the normal control, all groups were subjected to cyclophosphamide $(200 \mathrm{mg} / \mathrm{kg}$, i.p.) toxicity on the first day. Enalapril at $10 \mathrm{mg} / \mathrm{kg}$ was used as a reference. The hydromethanolic crude extract (100, 200, and $400 \mathrm{mg} / \mathrm{kg}$ ) and aqueous and ethyl acetate fractions (100 and $200 \mathrm{mg} / \mathrm{kg}$, each) were administered for 10 days. The cardioprotective activities were evaluated using cardiac biomarkers such as Troponin I, aspartate aminotransferase (AST), alanine aminotransferase (ALT), alkaline phosphatase (ALP), total cholesterol (TC), triglyceride (TG), and histopathological studies of heart tissue. Results. Crude extract and ethyl acetate and aqueous fractions exhibited free radical scavenging activities at $\mathrm{IC}_{50} \mathrm{of} 594 \mu \mathrm{g} /$ $\mathrm{mL}, 419 \mu \mathrm{g} / \mathrm{mL}$, and $716 \mu \mathrm{g} / \mathrm{mL}$, respectively. Crude extract at $400 \mathrm{mg} / \mathrm{kg}$ decreased the levels of troponin, AST, ALT, and ALP to $0.29 \pm 0.06 \mathrm{ng} / \mathrm{mL}, 103.00 \pm 7.63 \mathrm{U} / \mathrm{L}, 99.80 \pm 6.18 \mathrm{U} / \mathrm{L}$, and $108.80 \pm 8.81 \mathrm{U} / \mathrm{L}$, respectively. In addition, ethyl acetate fraction at $200 \mathrm{mg} / \mathrm{kg}$ decreased the levels of troponin, AST, ALT, and ALP to $0.22 \pm 0.02 \mathrm{ng} / \mathrm{mL}, 137.00 \pm 14.30 \mathrm{U} / \mathrm{L}, 90.33 \pm 6.13 \mathrm{U} / \mathrm{L}$, and $166.67 \pm 13.50 \mathrm{U} / \mathrm{L}$, respectively, compared with the cyclophosphamide control group. Conclusions. Croton macrostachyus possesses cardioprotective activities and it could be a possible source of treatment for cardiotoxicity induced by cyclophosphamide.
\end{abstract}

\section{Introduction}

Cardiotoxicity induced by drugs poses a serious risk to human health and is becoming an increasingly important concern in cardiooncology [1]. Improvements in antineoplastic treatments led to increased overall and progressionfree survival in the management of an increasing number of malignancies [2]. However, as cancer survival has improved with advancing therapy, late cardiovascular side effects have become an important management issue, particularly in childhood cancers, lymphoma, leukemia, and breast cancer [3].
Cancer survivors, when compared with their healthy counterparts, are at high risk of cardiovascular-related deaths, including myocardial infarction with coronary artery disease, cardiomyopathy with congestive heart failure, and cerebrovascular events $[4,5]$. People on cardiotoxic chemotherapy can be considered as a stage A group of heart failure patients [6].

Anticancer drugs are well known to cause a wide array of toxicities, including cardiac damage; these may include cardiac dysfunction leading to heart failure, myocardial ischemia, arrhythmias, hypertension, myocarditis, pericarditis, and thromboembolism [7]. Alkylating drugs, including 
cisplatin, cyclophosphamide, ifosfamide, carmustine, chlormethine, busulfan, and mitomycin are especially associated with cardiac toxicity [8].

Mechanisms of cyclophosphamide-induced cardiotoxicity encompass oxidative and nitrative stress, protein adduct formation which leads to cardiomyocyte inflammation, altered calcium homeostasis, programmed cell death, swelling of the cardiomyocytes, nuclear splitting, vacuolization, and alteration in signaling pathways. These events result in diseases of the heart muscle including heart failure, and if left untreated, this may result in death [9].

Cyclophosphamide-induced cardiac damage is dosedependent and the total dose of an individual course is the best indicator of toxicity; patients who receive greater than $150 \mathrm{mg} / \mathrm{kg}$ or $1.55 \mathrm{~g} / \mathrm{m} 2 /$ day are at high risk for cardiotoxicity [10]. Cardiotoxicity is a dose-limiting factor during cyclophosphamide therapy [11]. Although fatal cardiomyopathy has been reported among $2-17 \%$ of patients, it depends on the regimen and the patient population [12].

Various natural antioxidants originated from medicinal plants, which are used for the treatment of different ailments throughout the world. Croton macrostachyus Hochst. ex Delile (Euphorbiaceae) is mostly known as rush foil or wideleaved croton in English. It is a deciduous tree of the family Euphorbiaceae, a very large family with 300 genera and 8,000 to 10,000 species. Eight of these species (Croton dichogamus Pax, Croton zambesicus Muell. Arg, Croton menyhartii Pax, Croton somalense, Croton schimperianus Müll. Arg, Croton sylvaticus Hochst. ex Krauss, Croton lobatus Linn., and Croton macrostachyus Hochst. ex Delile) are found in Ethiopia [13].

Traditional healers use Croton macrostachyus to treat various human diseases [14]. Some of these ethnomedicinal uses of Croton macrostachyus were validated in several experimental studies. The plant showed antibacterial [15], antidiarrheal [16], anticonvulsant [17], antidiabetic [14], and antihyperalgesic activity [18].

The phytochemical screening showed that the stem bark of Croton macrostachyus constituted the major secondary metabolites such as tannins, steroids, alkaloids, phenols, terpenoids, saponins, and flavonoids, which might be the reason for the plant widespread pharmacological activity $[19,20]$.

Though Croton macrostachyus Hochst. ex Delile has been used in Ethiopian traditional medicine to treat different ailments including heart diseases, scientific investigation on pharmacological actions related to the cardioprotective activity has not been carried out. Therefore, the present study investigates an in vitro antioxidant activity and in vivo cardioprotective effects of Croton macrostachyus on cyclophosphamide-induced cardiotoxicity in rats.

\section{Materials and Methods}

2.1. Chemicals, Reagents, and Drugs. Cyclophosphamide injection IP (Cadila Healthcare Limited, India), ketamine hydrochloride (Neon Laboratories Limited, India), 2, 2diphenyl-1-picrylhydrazyl (DPPH) (Tokyo Chemical Industry Co., Ltd., Japan), methanol (Carlo Erba Reagents
S.A.S), ethyl acetate, n-hexane (Loba Chemie PVT. Ltd.), formalin 10\% (Sheba Pharmaceuticals PLC, Ethiopia), normal saline (Addis Pharmaceutical Factory, Ethiopia), and distilled water (Jourilabs, Ethiopia) were used. All other chemicals used were also of analytical grade.

2.2. Collection of Plant Material. Fresh Croton macrostachyus stem bark was collected on 25/11/2018 from AbiyAdi, Tigray, Ethiopia, $101.5 \mathrm{~km}$ away from the regional capital Mekelle, and 1,031 km towards North from Addis Ababa, Ethiopia. Identification and authentication of the plant were carried out at the Department of Plant Biology and Biodiversity Management, Addis Ababa University, and sample specimen was deposited at the National Herbarium of Ethiopia with Ref. No. ETH/4/2011/2019.

\subsection{Preparation of Crude Extract and Solvent Fractions.} The collected fresh stem bark was washed in order to remove dead materials and dust and then allowed to dry for three weeks under a shade. The dried stem bark was then pulverized, using a grinder. The powder $(1.52 \mathrm{~kg})$ was then macerated in $80 \%$ methanol for $72 \mathrm{~h}$ in maceration jars; extraction was aided by an orbital shaker and intermittent stirring.

For exhaustive extraction of the plant material, the residue was remacerated for another $72 \mathrm{~h}$ twice. The extract was then filtered using a muslin cloth followed by Whatman filter paper No. 1. The combined filtrates were dried in an oven at a temperature of $40^{\circ} \mathrm{C}$. Then, the dried extract (crude extract) was weighed and kept in a tightly closed amber bottle and stored in a refrigerator at $4^{\circ} \mathrm{C}$ until further use.

Fractionation was carried out using a separatory funnel. Sixty-five grams of the crude extract was dissolved in $325 \mathrm{~mL}$ of distilled water. Then, the extraction was performed by using $325 \mathrm{~mL}$ hexane, for three consecutive times, followed by $325 \mathrm{~mL}$ ethyl acetate again three times in order to attain complete fractionation. After collecting the hexane and ethyl acetate fractions, the remaining residue was considered as an aqueous fraction. The fractions were concentrated using an oven dryer at $40^{\circ} \mathrm{C}$ and weighed. Hexane fraction was yellowish oily. Dried powders of the aqueous and ethyl acetate fractions were kept in an airtight container and stored in a refrigerator at $4^{\circ} \mathrm{C}$ until further use.

2.4. Experimental Animals. Female Swiss albino mice aged 8-12 weeks were used for the acute toxicity study. For the main study, either sex of Sprague-Dawley (SD) rats (3-4 months ages) was obtained from the Department of Pharmacology and Toxicology, School of Pharmacy, Mekelle University. Animals were housed in a room with a $12 \mathrm{~h}$ light/ dark cycles and provided with standard pellet feed and water ad libitum.

The animals were acclimatized to the experimental environment prior to use for the study. All the experiments were conducted in accordance with the international laboratory animal use and care guideline. The study clearance was obtained from the Health Research Ethics Review 
Committee (HRERC) of the College of Health Sciences, Mekelle University with protocol number 1536/2018.

2.5. Acute Oral Toxicity Test. The acute oral toxicity test was carried out according to the Organization for Economic Cooperation and Development Guideline No. 425 [21]. Five healthy, nulliparous, nonpregnant female Swiss albino mice (aged 8-12 weeks) weighing 25-30 g were used for this test. The mice were fasted for food but not water $4 \mathrm{~h}$ prior to dosing and $1 \mathrm{~h}$ after the administration of the extract.

A single dose of the extract $(2000 \mathrm{mg} / \mathrm{kg})$ was administered using oral gavage to the first mouse which was subsequently observed for any physical and behavioral changes. After 24 hours, $2000 \mathrm{mg} / \mathrm{kg}$ single dose was administered orally to each of the remaining four mice. The mice were then observed individually for gross behavioral changes (locomotion, activity, hair texture, pupil size, and feeding) at least once during the first $30 \mathrm{~min}$, periodically for $24 \mathrm{~h}$, with special attention given during the first $4 \mathrm{~h}$, and daily observation were made thereafter for a total period of 14 days.

2.6. Determination of Antioxidant Activity (DPPH) Assay. To determine the free radical scavenging activity of the crude extract and solvent fractions, the in vitro DPPH assay method was used [22]. $3 \mathrm{~mL}$ of $0.004 \% \mathrm{DPPH}$ in methanol was mixed with $1 \mathrm{~mL}$ of different concentrations $(200,100$, 50,25 , and $12.5 \mu \mathrm{g} / \mathrm{mL}$ ) of crude and solvent fraction of Croton macrostachyus and ascorbic acid (a reference compound) separately. The mixture was vortexed and left for half hour at room temperature in the dark for incubation, and then, the absorbance of the mixture in the samples was measured using a spectrophotometer at $517 \mathrm{~nm}$ against methanol as blank. Lower absorbance values of reaction mixture designate higher free radical scavenging activity. Percentage radical scavenging activities of the test samples were calculated by comparison with a control $(3 \mathrm{~mL} \mathrm{DPPH}$ solution mixed with $1 \mathrm{~mL}$ methanol). All samples were measured in triplicate and the average was calculated.

The percentage of radical scavenging activity (RSA) was calculated using the following formula:

$$
\% \operatorname{RSA}=\left[\frac{(A 0-A 1)}{A 0}\right] \times 100,
$$

where $A 0$ is the absorbance of the control, and $A 1$ is the absorbance of samples.

The free radical scavenging activity of the extracts and ascorbic acid was expressed as a half-maximal inhibitory concentration (IC50). The IC50 value is defined as concentration (in $\mu \mathrm{g} / \mathrm{mL}$ ) of the sample that inhibits $50 \%$ of the $\mathrm{DPPH}$ radical.

2.7. Grouping and Dosing of Animals. To evaluate the cardioprotective activity, cyclophosphamide-induced cardiotoxicity damage method was used, as described by Mythili et al. [23], Viswanatha Swamy et al. [24], Alhumaidha et al. [25], Bhatt et al. [26], and Ogunsanwo et al.
[27]. The rats were divided into thirteen groups (Table 1); each group consist of six animals.

For the crude extract and aqueous fractions, group I served as normal control (NC) (received normal saline orally for 10 days), group II served as cyclophosphamide (CP) control (received a single dose of CP at $200 \mathrm{mg} / \mathrm{kg}$, i.p, dissolved in normal saline on the first day of the experiment period), group III served as standard control (received CP at $200 \mathrm{mg} / \mathrm{kg}$, i.p, on the first day and then enalapril at $10 \mathrm{mg} /$ $\mathrm{kg}$ orally for 10 days), and groups IV-VIII were treatment groups (received CP at $200 \mathrm{mg} / \mathrm{kg}$, i.p, on the first day and then three doses of crude extract, 100,200 , and $400 \mathrm{mg} / \mathrm{kg}$, and 100 and $200 \mathrm{mg} / \mathrm{kg}$ of the aqueous fraction dissolved in normal saline orally for 10 days, respectively). For the ethyl acetate fraction, group IX served as normal control (NC) (received 2\% dimethyl sulfoxide (DMSO) orally for 10 days), group $\mathrm{X}$ served as CP control (received a single dose of CP at $200 \mathrm{mg} / \mathrm{kg}$, i.p, on the first day of the experiment period), group XI served as standard control (received CP at $200 \mathrm{mg} / \mathrm{kg}$, i.p, on the first day and then enalapril $10 \mathrm{mg} / \mathrm{kg}$ orally for 10 days), and groups XII and XIII served as treatment group (received CP at $200 \mathrm{mg} / \mathrm{kg}$, i.p, on the first day and then 100 and $200 \mathrm{mg} / \mathrm{kg}$ of the ethyl acetate fraction dissolved in $2 \%$ dimethyl sulfoxide orally for 10 days, respectively).

2.8. Blood Collection. After $24 \mathrm{~h}$ of the last dose, all rats were anesthetized under ketamine anesthesia (75 mg/kg, i.p) and blood was collected by the retroorbital puncture using microcapillary tubes. Then, the serum was separated through centrifugation at $5000 \mathrm{rpm}$ for $10 \mathrm{~min}$ and used for the estimation of marker enzymes.

2.9. Determination of Cardiac Markers. The separated serum was used for the estimation of marker enzymes. Troponin I was determined using CS-200 acute care analyzer whereas aspartate aminotransferase (AST), alanine aminotransferase (ALT), alkaline phosphatase (ALP), total cholesterol (TC), and triglyceride (TG) levels were measured using BTS 350 semiautomated biochemistry analyzer.

2.10. Histopathological Examination. The heart was immediately removed from animals and washed with water and blotted dry with filter paper and weighed and then fixed in $10 \%$ formalin for histopathological analysis. Histological sections of the heart were stained with hematoxylin and eosin (H\&E). Heart sections were observed for myocyte damage, multifocal degeneration, inflammation, myofibrillar degeneration, and necrosis.

2.11. Statistical Analysis. The data were expressed as means \pm standard error of the mean (SEM). The analysis was carried out using the statistical package for social science (SPSS version 20.0). One-way analysis of variance (ANOVA) followed by Tukey's post hoc test was applied to compare variations among groups. $P<0.05$ was considered statistically significant. 
TABLE 1: Grouping and dosing of rats used in experiments (AQ: aqueous fraction; CE: crude extract; EA: ethyl acetate fraction).

\begin{tabular}{lc}
\hline Treatment groups & Dose \\
\hline Treatment groups (CE and AQ) & \\
Normal control (0.9\% normal saline) & $0.5 \mathrm{~mL} / 100 \mathrm{~g}$ \\
Cyclophosphamide (CP) control & $200 \mathrm{mg} / \mathrm{kg}$ \\
Standard control—enalapril (EN) & $10 \mathrm{mg} / \mathrm{kg}$ \\
Crude extract (CE 100) & $100 \mathrm{mg} / \mathrm{kg}$ \\
Crude extract (CE 200) & $200 \mathrm{mg} / \mathrm{kg}$ \\
Crude extract (CE 400) & $400 \mathrm{mg} / \mathrm{kg}$ \\
Aqueous fraction (AQ 100) & $100 \mathrm{mg} / \mathrm{kg}$ \\
Aqueous fraction (AQ 200) & $200 \mathrm{mg} / \mathrm{kg}$ \\
\hline Treatment groups (EA) & \\
Normal control (2\% DMSO) & $0.5 \mathrm{~mL} / 100 \mathrm{~g}$ \\
Cyclophosphamide (CP) control & $200 \mathrm{mg} / \mathrm{kg}$ \\
Standard control-enalapril (EN) & $10 \mathrm{mg} / \mathrm{kg}$ \\
Ethyl acetate fraction (EA 100) & $100 \mathrm{mg} / \mathrm{kg}$ \\
Ethyl acetate fraction (EA 200) & $200 \mathrm{mg} / \mathrm{kg}$ \\
\hline
\end{tabular}

\section{Results}

3.1. Extraction Yields of Plant Material. The percentage yield of crude extract was $6.68 \%$. Among the fractions, the aqueous fraction was the one with the highest yield at $56.46 \%$. The ethyl acetate fraction was $17.53 \%$.

3.2. Acute Oral Toxicity Test. Administration of $2000 \mathrm{mg} / \mathrm{kg}$ of the Croton macrostachyus did not produce any sign of toxicity. It did not cause changes in breathing, alertness, and motor activity. There were no restlessness, diarrhea, coma, and convulsions in the two-week follow-up period. Therefore, the LD50 of the crude extract can be considered to be higher than $2000 \mathrm{mg} / \mathrm{kg}$.

3.3. DPPH Free Radical Scavenging Activity. The ethyl acetate fraction exhibited the highest free radical scavenging activity with $\mathrm{IC}_{50}$ of $419 \mu \mathrm{g} / \mathrm{mL}$ when compared with crude extract and aqueous fraction ( $\mathrm{IC}_{50}$ of $594 \mu \mathrm{g} / \mathrm{mL}$ and $716 \mu \mathrm{g} / \mathrm{mL}$, respectively). The $\mathrm{IC}_{50}$ of standard solution (ascorbic acid) was $30.612 \mu \mathrm{g} / \mathrm{mL}$ with $R^{2}=0.975$.

3.4. Effect of Crude Extract and Solvent Fractions on Body Weight. As shown in Table 2, significant weight loss was observed in the cyclophosphamide-treated group when compared with a normal control group $(P<0.001)$. However, the treatments with $100 \mathrm{mg} / \mathrm{kg}$ crude extract and $10 \mathrm{mg} / \mathrm{kg}$ enalapril significantly prevented weight loss compared with the group treated with cyclophosphamide alone $(P<0.05$ and $P<0.01)$. Treatment with aqueous fractions also significantly prevented the weight loss compared with the cyclophosphamide control group $(P<0.001)$ (Table 2).

In the ethyl acetate fraction group, the administration of cyclophosphamide resulted in significant weight loss when compared with the normal group animals $(P<0.001)$. Treatment with ethyl acetate fraction (100 and $200 \mathrm{mg} / \mathrm{kg}$ ) and enalapril (10 mg/kg) prevented weight loss significantly when compared with the cyclophosphamide control group $(P<0.001)$ (Table 3).

\subsection{Effect of Crude Extract and Solvent Fractions on} Heart Weight and Heart-to-Body Weight Ratio. Cyclophosphamide significantly $(P<0.001)$ increased heart weight as well as the heart-to-body weight ratio compared with the normal control group (Table 2). $400 \mathrm{mg} / \mathrm{kg}$ crude extract and $10 \mathrm{mg} / \mathrm{kg}$ enalapril treatment significantly prevented heart weight increment when compared with cyclophosphamide-treated group $(P<0.001)$. Moreover, treatment with crude extract at 100 and $200 \mathrm{mg} / \mathrm{kg}$ significantly prevented heart weight increment compared with cyclophosphamide-treated group $(P<0.01)$.

Similarly, treatment with enalapril at $10 \mathrm{mg} / \mathrm{kg}$ and aqueous and ethyl acetate fractions at 100 and $200 \mathrm{mg} / \mathrm{kg}$ decreased heart-to-body weight ratio significantly compared with the cyclophosphamide control group $(P<0.001)$ (Table 3).

3.6. Effect of Crude Extract and Solvent Fractions on Cardiac Biomarkers. Serum cardiac biomarkers such as troponin $(P<0.01)$ and AST, ALT, and ALP $(P<0.001)$ were significantly increased by the administration of cyclophosphamide compared with normal control animals (Figure 1). Treatment with crude extract and aqueous fraction significantly decreased the levels of AST, ALT, and ALP compared with the cyclophosphamide-treated group $(P<0.001)$. The crude extract $(400 \mathrm{mg} / \mathrm{kg})$ decreased troponin level significantly compared with the cyclophosphamide-treated group $(P<0.05)$.

Likewise, treatment with ethyl acetate fraction (100 and $200 \mathrm{mg} / \mathrm{kg}$ ) significantly decreased serum cardiac biomarkers compared with cyclophosphamide. Ethyl acetate fraction (100 and $200 \mathrm{mg} / \mathrm{kg}$ ) significantly reduced the troponin level; the reduction is comparable to enalapriltreated animals (Figure 2).

\subsection{Effect of Crude Extract and Solvent Fractions on Lipid} Profile. Cyclophosphamide administration significantly increased both TG and TC levels compared with normal control group of animals $(P<0.001)$. All treatment groups significantly decreased both TG and TC levels when compared with cyclophosphamide-treated group of animals (Figures 3 and 4).

3.8. Histopathological Studies. To determine the cardioprotective activity of Croton macrostachyus, a histopathologic examination was carried out in heart tissues. As shown in Figures 5 and 6, normal structures of the heart with no necrosis were observed in normal control animals. Rats treated with cyclophosphamide showed congestion, degeneration of myocardial tissue, and necrosis. Enalapriltreated groups exhibited mild diffused focal hemorrhage and necrosis. In the treatment groups with crude extract and solvent fractions of Croton macrostachyus, focal necrosis and 
TABLE 2: Effects of crude extract and aqueous fraction on body weight, heart weight, and heart-to-body weight ratio.

\begin{tabular}{lcccc}
\hline Group & Dose & Relative weight changes $(\mathrm{g})$ & Heart weight $(\mathrm{g})$ & Heart-to-body wt. ratio $\left(\times 10^{-3}\right)$ \\
\hline $\mathrm{NC}$ & $\mathrm{NS}(0.5 \mathrm{~mL} / 100 \mathrm{~g})$ & $+6.0 \pm 5.24$ & $0.91 \pm 0.01$ & $2.77 \pm 0.06$ \\
\hline $\mathrm{CP}$ & $200 \mathrm{mg} / \mathrm{kg}$ & $-101.33 \pm 7.88^{* * *}$ & $1.17 \pm 0.04^{* * *}$ & $5.53 \pm 0.17^{* * *}$ \\
\hline \multirow{2}{*}{$\mathrm{EN}$} & $10 \mathrm{mg} / \mathrm{kg}$ & $-65.8 \pm 5.07^{\# \#}$ & $0.89 \pm 0.02^{\# \# \#}$ & $3.69 \pm 0.28^{\# \# \#}$ \\
& $100 \mathrm{mg} / \mathrm{kg}$ & $-68.5 \pm 5.63^{\#}$ & $1.01 \pm 0.02^{\# \#}$ & $3.71 \pm 0.15^{\# \# \#}$ \\
\hline \multirow{2}{*}{$\mathrm{CE}$} & $200 \mathrm{mg} / \mathrm{kg}$ & $-75.0 \pm 5.02$ & $0.99 \pm 0.01^{\# \#}$ & $3.86 \pm 0.19^{\# \# \#}$ \\
& $400 \mathrm{mg} / \mathrm{kg}$ & $-76.0 \pm 6.22$ & $0.88 \pm 0.02^{\# \# \#}$ & $3.74 \pm 0.19^{\# \# \#}$ \\
\multirow{2}{*}{$\mathrm{AQ}$} & $100 \mathrm{mg} / \mathrm{kg}$ & $-66.33 \pm 4.07^{\# \#}$ & $0.87 \pm 0.01^{\# \# \#}$ & $4.16 \pm 0.11^{\# \# \#}$ \\
& $200 \mathrm{mg} / \mathrm{kg}$ & $-64.33 \pm 3.40^{\# \# \#}$ & $0.85 \pm 0.01^{\# \# \#}$ & $3.98 \pm 0.11^{\# \# \#}$ \\
\hline
\end{tabular}

Results are expressed as mean $\pm \operatorname{SEM}(n=6) .{ }^{* * *} P<0.001$ when compared with normal control; ${ }^{\#} P<0.05,{ }^{\# \#} P<0.01$ and ${ }^{\# \# \#} P<0.001$ when compared with $\mathrm{CP}$ control. AQ: aqueous fraction; CP: cyclophosphamide; CE: crude extract; EN: enalapril; NC: normal control; NS: normal saline.

TABLE 3: Effects of ethyl acetate fraction on body weight, heart weight, and heart-to-body weight ratio.

\begin{tabular}{lcccc}
\hline Group & Dose & Relative weight changes $(\mathrm{g})$ & Heart weight $(\mathrm{g})$ & Heart-to-body wt. ratio $\left(\times 10^{-3}\right)$ \\
\hline NC & $2 \%$ DMSO $(0.5 \mathrm{~mL} / 100 \mathrm{~g})$ & $+8.0 \pm 1.24$ & $0.58 \pm 0.04$ & $2.16 \pm 0.13$ \\
\hline CP & $200 \mathrm{mg} / \mathrm{kg}$ & $-125.0 \pm 1.23^{* * *}$ & $0.81 \pm 0.03^{* * *}$ & $5.37 \pm 0.23^{* * *}$ \\
\hline EN & $10 \mathrm{mg} / \mathrm{kg}$ & $-93.17 \pm 4.03^{\#}$ & $0.54 \pm 0.03^{\# \# \#}$ & $3.67 \pm 0.07^{\# \# \#}$ \\
\hline \multirow{2}{*}{ EA } & $100 \mathrm{mg} / \mathrm{kg}$ & $-95.83 \pm 10.56^{\#}$ & $0.70 \pm 0.03$ & $3.77 \pm 0.17^{\# \# \#}$ \\
& $200 \mathrm{mg} / \mathrm{kg}$ & $-95.33 \pm 10.66^{\#}$ & $0.69 \pm 0.02$ & $3.63 \pm 0.06^{\# \# \#}$ \\
\hline
\end{tabular}

Results are expressed as mean $\pm \operatorname{SEM}(n=6) .{ }^{* * *} P<0.001$ when compared with normal control; ${ }^{\#} P<0.05$ and ${ }^{\# \# \#} P<0.001$ when compared with CP control. EA: ethyl acetate fraction; CP: cyclophosphamide; CE: crude extract; EN: enalapril; NC: normal control; DMSO: dimethyl sulfoxide.

hyperplasia of muscle fiber were observed, but the damage was decreased in all treatment groups (Figures 5 and 6).

\section{Discussion}

Cyclophosphamide is an alkylating agent used for cancer management [28]. It is broadly used for the treatment of leukemias, lymphomas, multiple myeloma, and rheumatic arthritis and prior to bone marrow transplantation [24]. Although it has a wide spectrum of therapeutic applications, it is a cardiotoxic drug leading to endothelial impairment and destruction of myocardiocytes [29]. One of the main reasons for cyclophosphamide-induced cardiotoxicity is oxidative stress [9]. Oxidative stress may result in endothelial dysfunction, hypertrophy, fibrosis, inflammation, apoptosis, cell migration, and angiogenesis [30].

Plants with naturally occurring antioxidant activity can be used to control homeostasis between free radicals and antioxidant stress. Medicinal plants, which are used traditionally, offer an important therapeutic effect in this regard [31].

This study set out to investigate whether Croton macrostachyus has cardioprotective and antioxidant effects. To evaluate the antioxidant activity of crude extract and solvent fractions, the DPPH assay method was used. The DPPH radical has an electron which is accountable for the absorbance at $517 \mathrm{~nm}$ and also for the observable deep purple color. During DPPH acceptance of an electron donated by an antioxidant, DPPH is decolorized to yellowish color which can be quantitatively measured from the changes in absorbance [32]. The crude extracts and solvent fractions were compared for their antioxidant activity based on their $\mathrm{IC}_{50}$ (concentration providing 50\% inhibition).
The crude extracts and solvent fractions of Croton macrostachyus stem bark demonstrated free radical scavenging activity. However, standard ascorbic acid has shown strong antioxidant activity than test samples.

The phytochemical studies reported showed that stem bark of Croton macrostachyus constituted major secondary metabolites such as flavonoids, phenols, terpenoids, saponins, tannins, alkaloids, and steroids [19, 20]. These phytochemicals were reported to have an antioxidant activity in previous studies [33-40].

Ethyl acetate fraction exhibited strong antioxidant activity with $\mathrm{IC}_{50}$ of $419 \mu \mathrm{g} / \mathrm{mL}$ relatively stronger than those of the crude extract and aqueous fractions. Ethyl acetate fraction is reported to have a high amount of total phenolics and total flavonoids [41, 42]. This could be increased due to the solubility of phenolics in ethyl acetate [43]. Thus, the highest free radical scavenging activity of the ethyl acetate fraction could be due to the presence of an increased amount of those antioxidant metabolites in higher proportions compared with the crude extract and aqueous fractions. This is similar to another finding where the ethyl acetate fraction of a different plant showed the highest radical scavenging activity [44].

In cardioprotective studies, the administration of cyclophosphamide caused a significant body weight loss compared with the normal group. This effect was consistent with previous studies [45-47]. This might be due to anorexia as a result of the damaging effect of cyclophosphamide on the gastrointestinal tract or on the appetite center (ventromedial nucleus and lateral hypothalamus) in the hypothalamus [24, 48].

Weight loss was prevented significantly by the administration of crude extract and fractions of aqueous and ethyl 


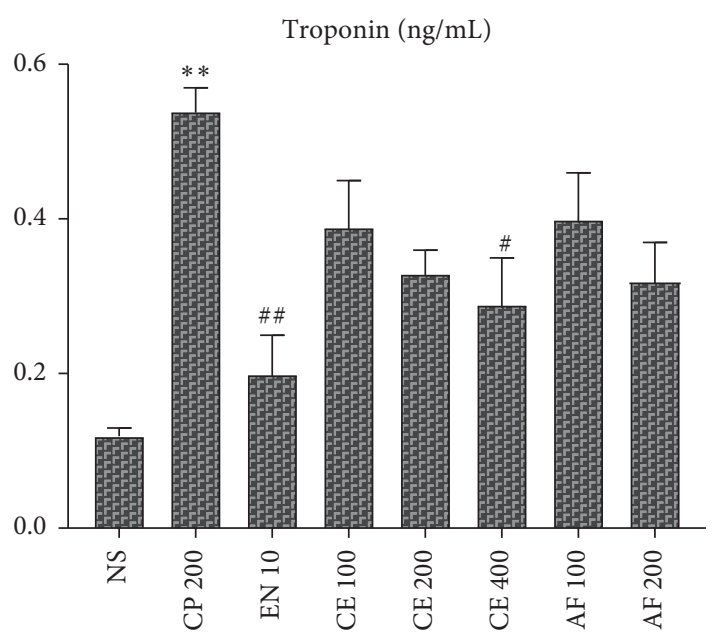

(a)

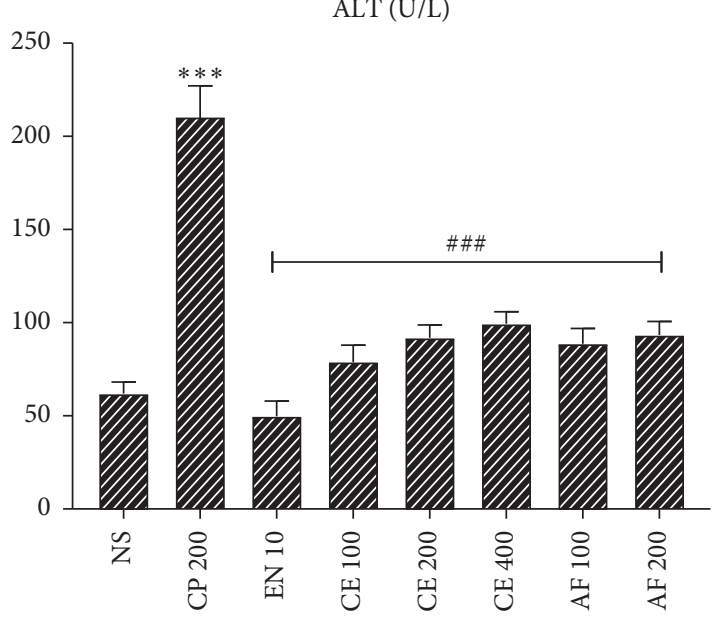

(c)

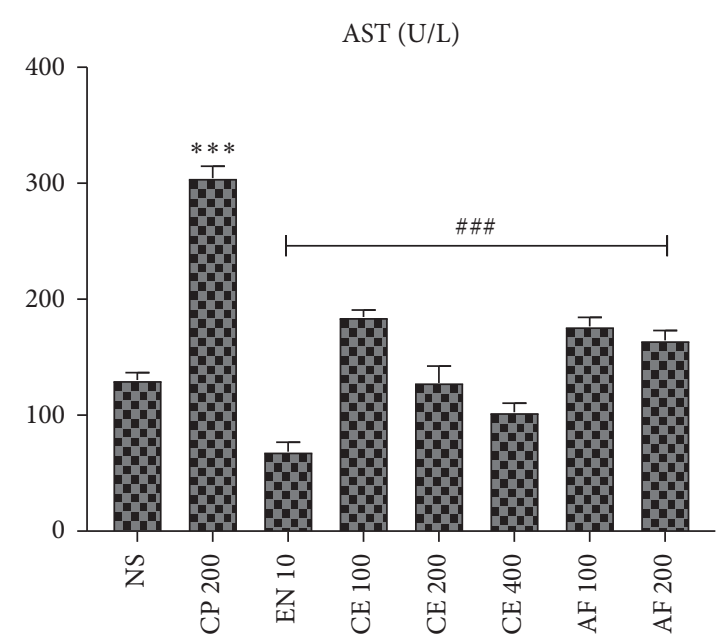

(b)

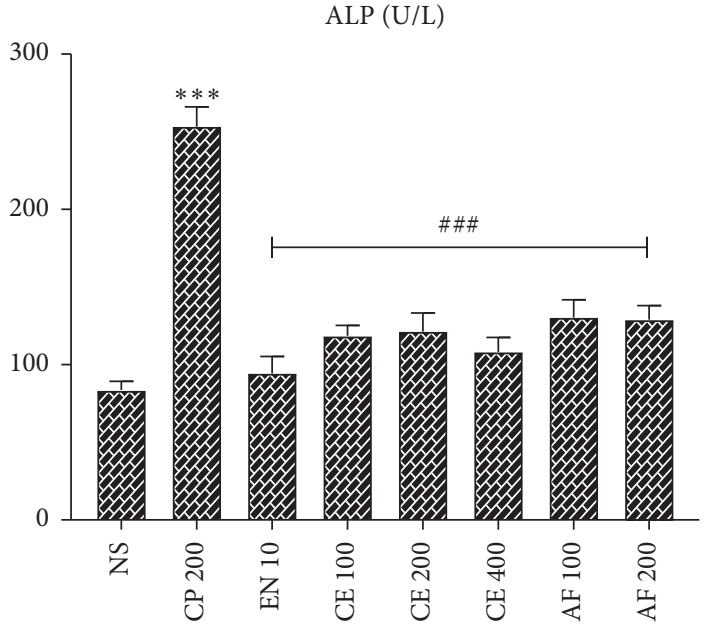

(d)

FIgURE 1: Effect of crude extract and aqueous fraction of Croton macrostachyus on the serum levels of (a) troponin, (b) aspartate aminotransferase (AST), (c) alanine aminotransferase (ALT), and (d) alkaline phosphatase (ALP). Results are expressed as mean \pm SEM $(n=6) .{ }^{* *} P<0.01,{ }^{* * *} P<0.001$ when compared wih normal control; ${ }^{\#} P<0.05$, ${ }^{\#} P<0.01$, and ${ }^{\# \# \#} P<0.001$ when compared with CP control. AF: aqueous fraction; CP: cyclophosphamide; CE: crude extract; EN: enalapril; NS: normal saline.

acetate. This may be due to the preventive ability of Croton macrostachyus against the damaging effect of cyclophosphamide on feeding behavior [48].

Data showed that cyclophosphamide significantly increased heart weight and heart-to-body weight ratio. These results are consistent with data presented by several researchers who worked on the cardioprotective effects of medicinal plants [26, 49]. Increment of heart weight might be due to the increased vascular hemorrhage, edema, and cardiac muscle fiber necrosis followed by the invasion of damaged tissues with inflammatory cells [24]; these effects can be confirmed by the qualitative histopathological observations elsewhere in this study. Treatment with crude extract and solvent fractions prevented the increase in heart weight and heart-to-body weight ratio. This could be attributed to the presence of flavonoids, which are reported to have a favorable effect on the heart by dilating the blood vessels resulting in reduced peripheral resistance and increased coronary circulation, delaying or preventing the progression to cardiac hypertrophy [48].

In the present study, $200 \mathrm{mg} / \mathrm{kg}$ cyclophosphamide administration has increased the levels of serum cardiac biomarkers (troponin, AST, ALT, and ALP). These results were in agreement with previous studies [24, 50]. Elevations of these enzymes in serum were associated with heart damage such as myocardial infarction, myocarditis, and heart failure [51]. This might be due to cyclophosphamideinduced direct myocardial endothelial damage and cardiomyocyte destruction or it can be due to the overproduction of reactive oxygen species accompanied by lipid peroxidation of cardiac membranes [52].

Administration of crude extract and solvent fractions of Croton macrostachyus decreased the release of cardiac biomarkers into the blood stream indicating amelioration of cardiac damage; this might be due to a reparative or 


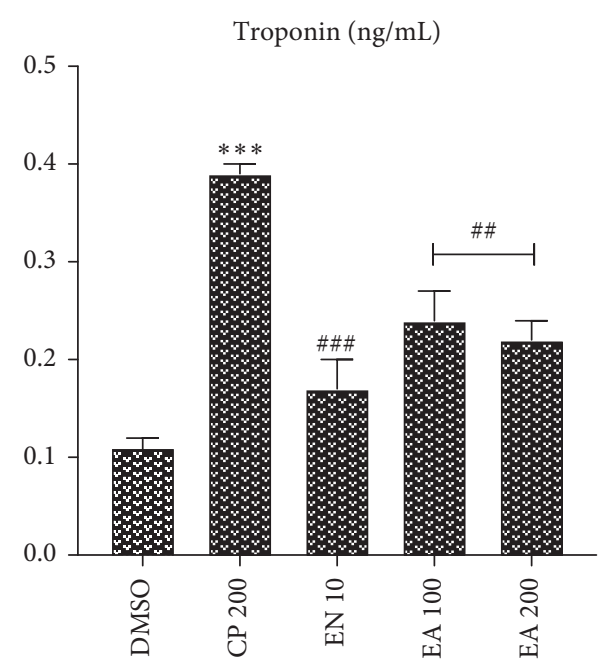

(a)

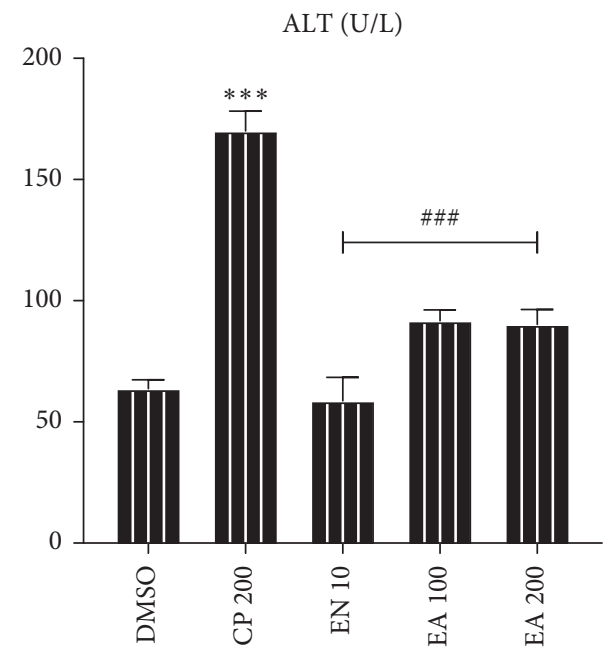

(c)

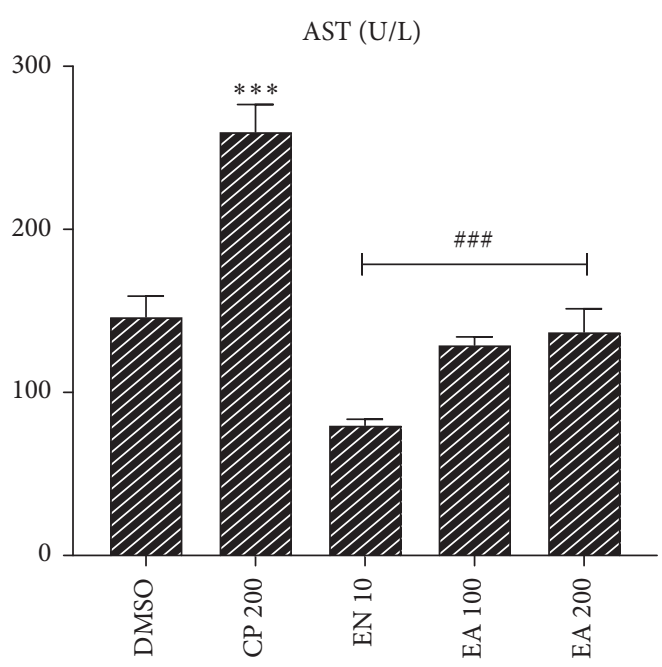

(b)

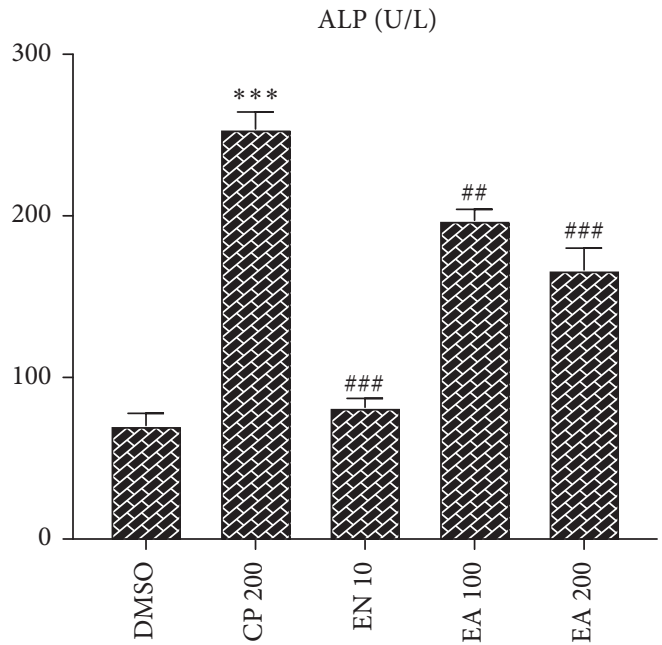

(d)

FIGURE 2: Effect of ethyl acetate fraction of Croton macrostachyus on the serum levels of (a) troponin, (b) aspartate aminotransferase (AST), (c) alanine aminotransferase (ALT), and (d) alkaline phosphatase (ALP). Results are expressed as mean \pm SEM $(n=6) .{ }^{* * *} P<0.001$ when compared with normal control; ${ }^{\#} P<0.05$, ${ }^{\#} P<0.01$, and ${ }^{\# \# \# ~} P<0.001$ when compared with CP control. DMSO: dimethyl sulfoxide; EA: ethyl acetate fraction; CP cyclophosphamide; CE: crude extract; EN: enalapril.

membrane-stabilizing action of Croton macrostachyus $[24,26,53]$. It might also be due to the presence of antioxidants phytochemicals with cardioprotective activity like flavonoids [54, 55] and alkaloids [56]. These results were in agreement with previously reported studies $[29,48]$; this observation can be mechanistically explained by the free radical scavenging activity of the Croton macrostachyus discussed above. The reductions in troponin, AST, and ALP levels were higher for $400 \mathrm{mg} / \mathrm{kg}$ of the crude extract compared with those of the two lower doses and the aqueous fraction. This could obviously be due to the increased levels of antioxidant phytoconstituents.

The inhibitory effect on xanthine oxidase activity might be another possible reason for the Croton macrostachyus protective effect. It was reported that cyclophosphamide increases myocardial xanthine oxidase activity and reduces the level of the antioxidant enzyme [9]. Xanthine oxidase is a flavoprotein, found in heart, kidney, lung, and vascular endothelium, which catalyzes the oxidation of hypoxanthine to xanthine and generates superoxide and uric acid and this leads to several diseases including CVDs [57]. In other studies, plants with antioxidant activity were also reported to have xanthine oxidase inhibitory activity $[58,59]$. Phytochemical constituents like flavonoids [60], alkaloids [61], and phenolic compounds [62] were reported to inhibit xanthine oxidase enzyme.

Inflammation plays a key role in the regulation of oxidative stress and cyclophosphamide was reported to induce inflammation in cardiomyocytes [63]. Inflammation was associated with pronounced cardiac damage like heart failure [64]. The stem bark extract of Croton macrostachyus was reported to have an anti-inflammatory effect and this might be one possible reason for its protective effect [19]. 


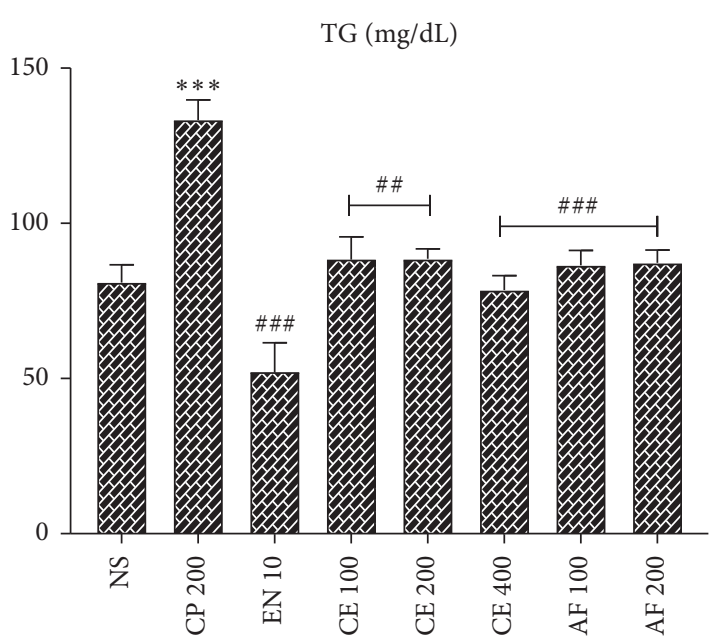

(a)

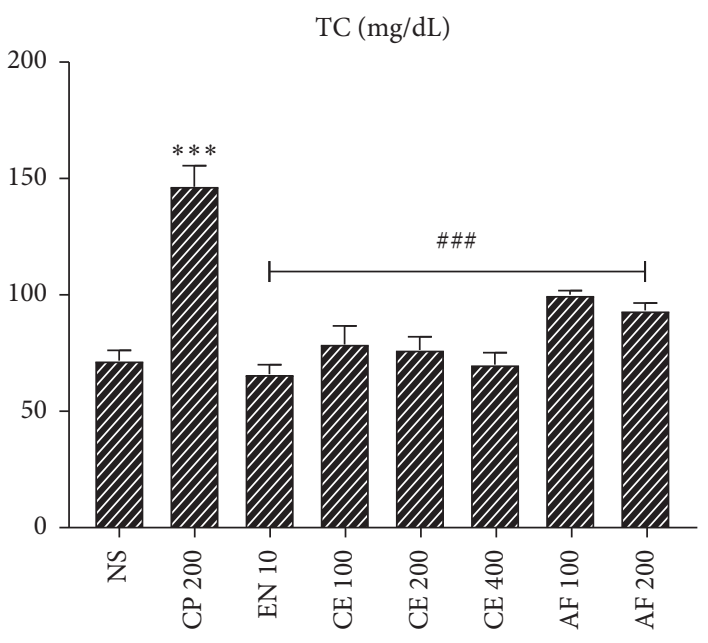

(b)

FIGURE 3: Effect of crude extract and aqueous fraction of Croton macrostachyus on the serum levels of (a) triglyceride (TG) and (b) total cholesterol (TC). Results are expressed as mean \pm SEM $(n=6)$. ${ }^{* * *} P<0.001$ when compared with normal control; ${ }^{\# \#} P<0.01$ and ${ }^{\# \# \#} P<0.001$ when compared with CP control. AF: aqueous fraction; CP: cyclophosphamide; CE: crude extract; EN: enalapril; NS: normal saline.

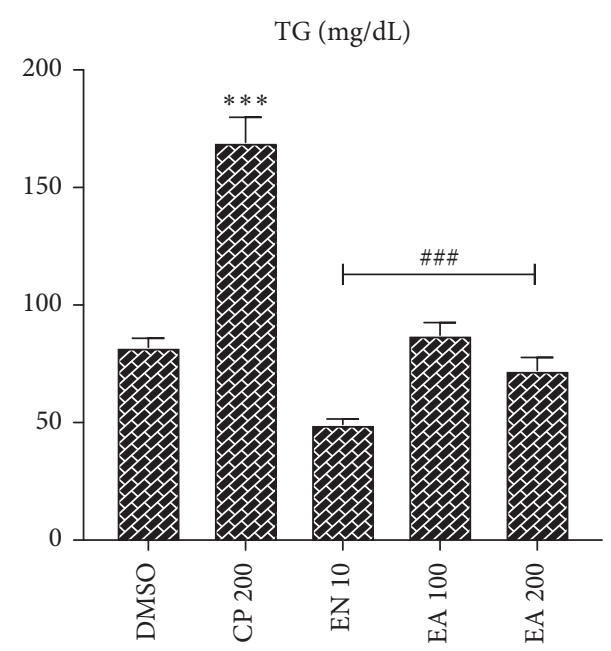

(a)

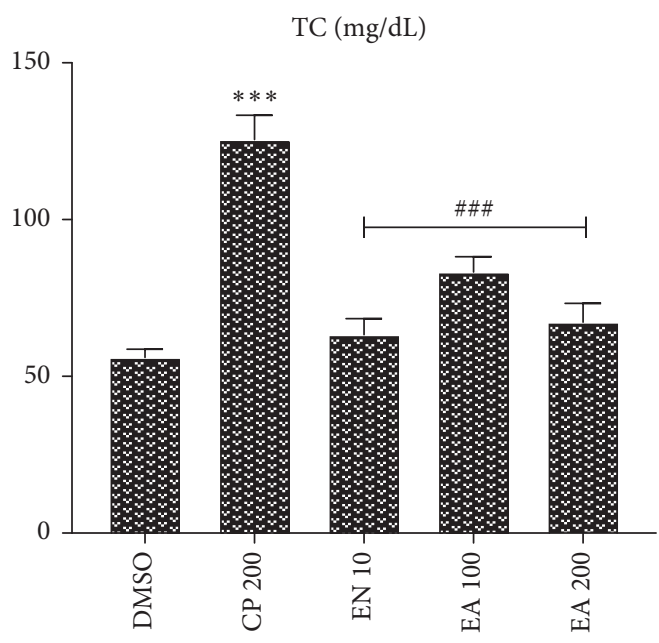

(b)

Figure 4: Effect of ethyl acetate fraction of Croton macrostachyus on the serum levels of (a) triglyceride (TG) and (b) total cholesterol (TC). Results are expressed as mean \pm SEM $(n=6) .{ }^{* * *} P<0.001$ when compared with normal control; ${ }^{\#} P<0.05$, ${ }^{\# \#} P<0.01$, and ${ }^{\# \# \#} P<0.001$ when compared with CP control. DMSO: dimethyl sulfoxide; EA: ethyl acetate fraction; CP: cyclophosphamide; CE: crude extract; EN: enalapril.

Cyclophosphamide administration significantly increased lipid profile (TG and TC) levels. This was similar to a previously reported study [24]. Oxidative stress impairs the cell removal of free cholesterol to high-density lipoprotein, which increases the amounts of cellular free cholesterol. Generally, cyclophosphamide-induced cardiomyopathy is associated with increased cholesterol biosynthesis and esterification, reduction in cell cholesteryl ester hydrolysis, and reduced cholesterol efflux. It was reported that antioxidants have the capability to inhibit all these mechanisms [65].

Treatment with crude extract and solvent fractions of Croton macrostachyus decreased both TG and TC levels near to normalcy. Crude extract and ethyl acetate fraction exhibited a dose-dependent effect on both levels. This preventive effect of Croton macrostachyus against cyclophosphamide-induced hyperlipidemic cardiomyopathy might be due to its antioxidant activity. Previously studies have elucidated the mechanistic association of antioxidant activity with hyperlipidemic cardiomyopathy $[26,66]$.

Histopathological findings of heart tissues further established the results regarding the effects of Croton macrostachyus on anatomical (heart mass index) and biochemical parameters (Figures 5 and 6). Heart sections of normal control rats revealed normal structures of heart, 


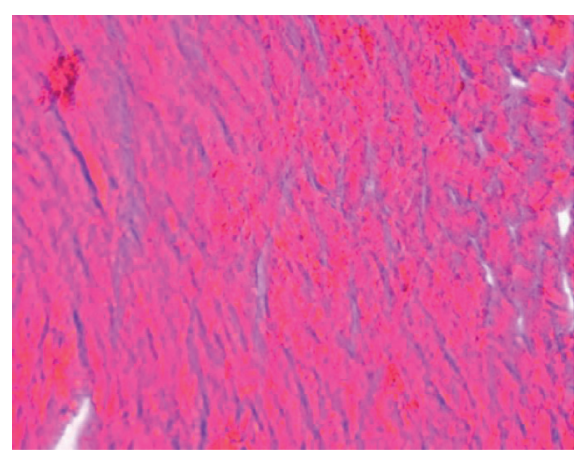

(a)

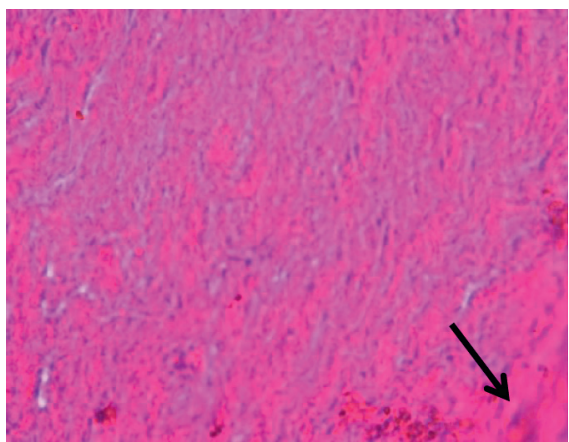

(c)

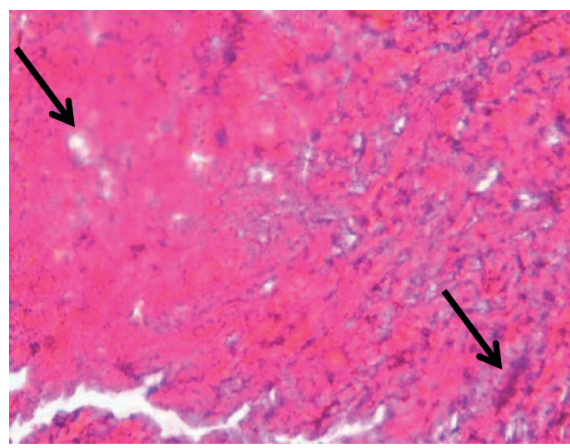

(e)

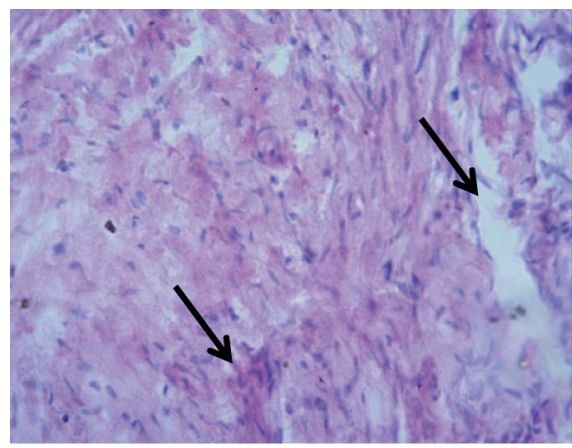

(g)

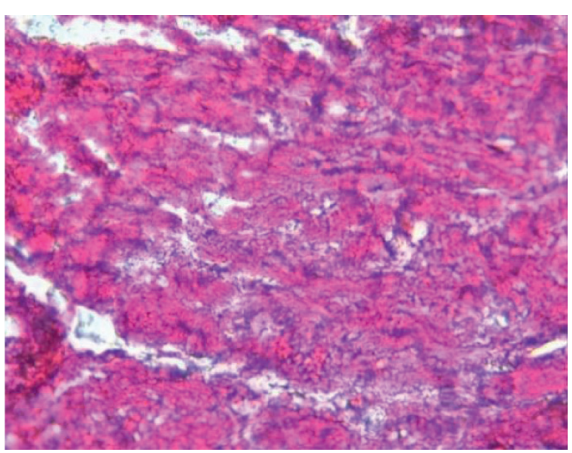

(b)

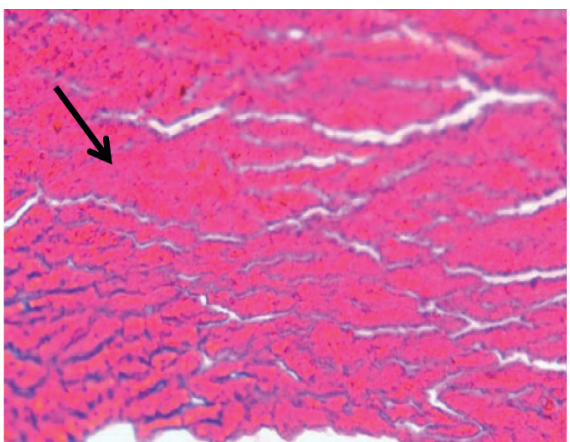

(d)

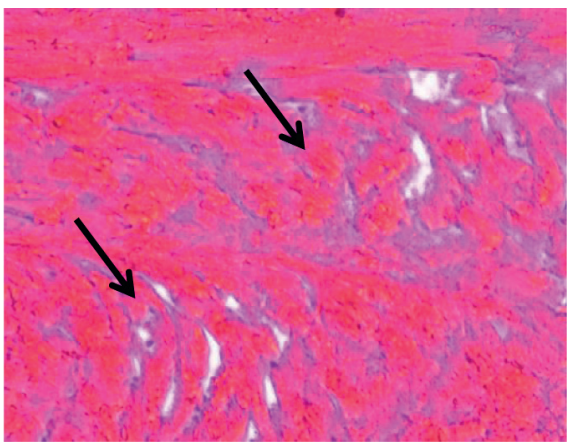

(f)

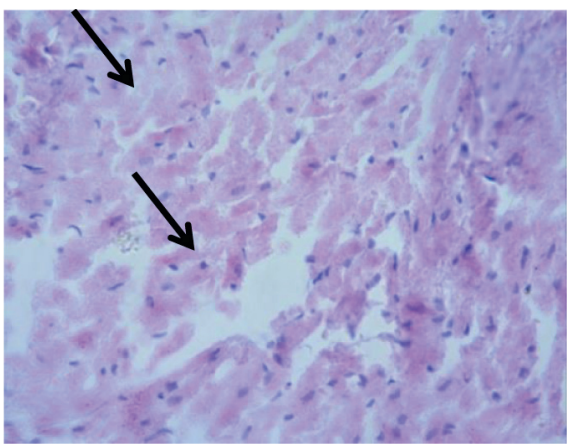

(h)

Figure 5: Histopathological changes in the heart tissue treated with crude extract and aqueous fraction. (a) Normal control group (normal structures of the heart). (b) Cyclophosphamide control group (congestion, degeneration of myocardial tissue, and necrosis). (c) Enalapril control group (mild necrosis). (d) Crude extract at $100 \mathrm{mg} / \mathrm{kg}$ (hypertrophy). (e) Crude extract at $200 \mathrm{mg} / \mathrm{kg}$ (edema and focal necrosis). (f) Crude extract at $400 \mathrm{mg} / \mathrm{kg}$ (edema). (g) Aqueous fraction at $100 \mathrm{mg} / \mathrm{kg}$ (edema and congestion). (h) Aqueous fraction at $200 \mathrm{mg} / \mathrm{kg}$ (edema and slight degeneration of myocardial tissue). 


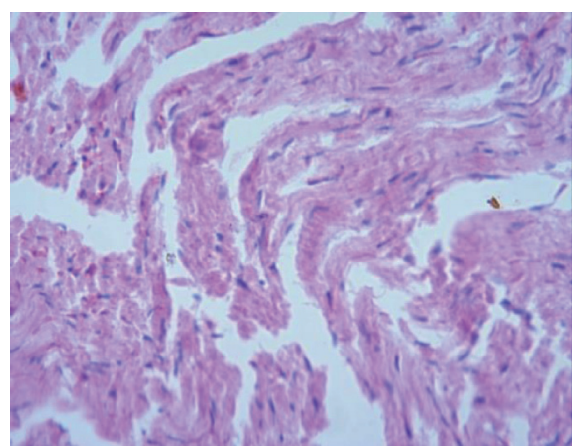

(a)

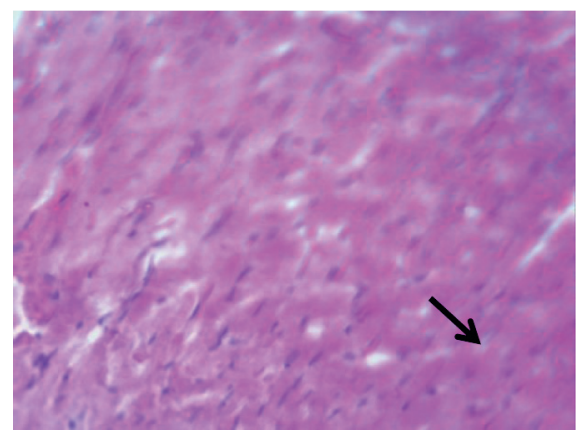

(c)

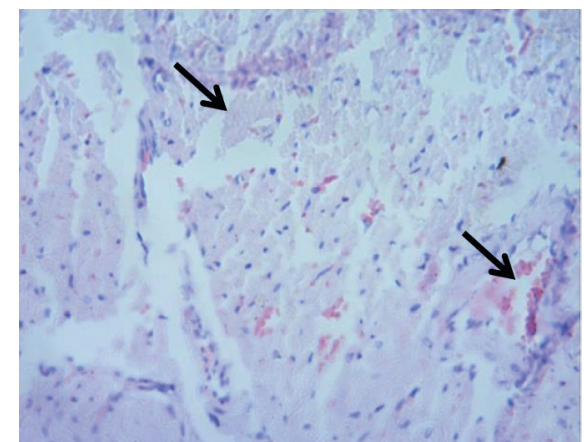

(b)

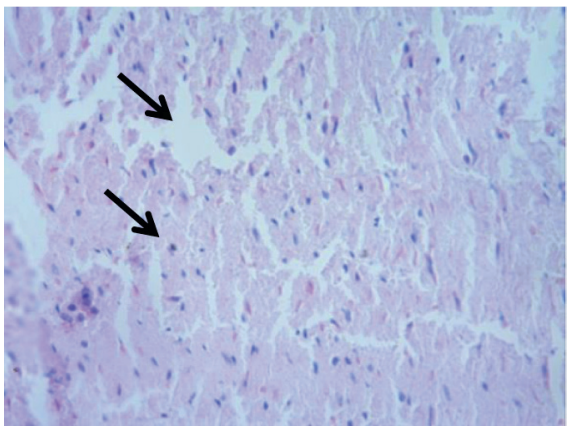

(d)

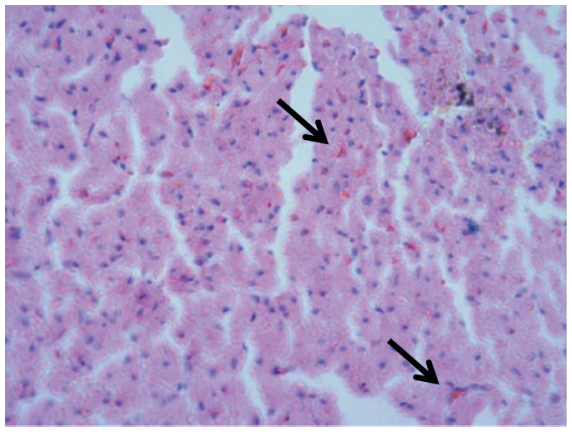

(e)

FIgURE 6: Histopathological changes in the heart tissue treated with ethyl acetate fraction. (a) Normal control group (normal structures of the heart). (b) Cyclophosphamide control group (necrosis and hemorrhage). (c) Enalapril control group (mild congestion and necrosis). (d) Ethyl acetate fraction at $100 \mathrm{mg} / \mathrm{kg}$ (nearly normal structure, edema). (e) Ethyl acetate fraction at $200 \mathrm{mg} / \mathrm{kg}$ (hemorrhage).

while rats administered with cyclophosphamide showed congestion, degeneration of myocardial tissue, and necrosis as a confirmation of cardiotoxicity. Reversals of such damage were observed in Croton macrostachyus and an enalapriltreated group of animals.

\section{Conclusion}

Hydromethanolic crude extract and ethyl acetate and aqueous fractions of Croton macrostachyus proved to have cardioprotective activity against cyclophosphamide-induced cardiotoxicity. We recommend further study on the isolation, identification, and characterization of the active component(s) of the extracts (especially from the ethyl acetate fraction) and elucidation of their possible molecular mechanism of action.

\section{Data Availability}

The datasets generated and/or analyzed during the current study are available from the corresponding author on reasonable request.

\section{Conflicts of Interest}

The authors declare that they have no conflicts of interest.

\section{Acknowledgments}

The authors thank Mekelle University for the financial support for this research. They are also grateful to Professor Sileshi Nemomissa, Department of Plant Biology and Biodiversity Management, Addis Ababa University, for identifying and authenticating the plant. 


\section{References}

[1] C. Cadeddu Dessalvi, M. Deidda, D. Mele et al., "Chemotherapy-induced cardiotoxicity: new insights into mechanisms, monitoring, and prevention," Journal of Cardiovascular Medicine, vol. 19, no. 7, pp. 315-323, 2018.

[2] G. Varricchi, P. Ameri, C. Cadeddu et al., "Antineoplastic drug-induced cardiotoxicity: a redox perspective," Frontiers in Physiology, vol. 9, p. 167, 2018.

[3] S. Kumar, R. K. Gupta, and N. Samal, "Cyclophosphamide cardiotoxicity," The National Medical Journal of India, vol. 5, no. 1, pp. 17-19, 1992.

[4] M. Csapo and L. Lazar, "Chemotherapy-induced cardiotoxicity: pathophysiology and prevention," Medicine and Pharmacy Reports, vol. 87, no. 3, pp. 135-142, 2014.

[5] R. W. Loar, C. V. Noel, H. Tunuguntla, J. L. Colquitt, and R. H. Pignatelli, "State of the art review: chemotherapy-induced cardiotoxicity in children," Congenital Heart Disease, vol. 13, no. 1, pp. 5-15, 2018.

[6] D. Cardinale and C. M. Cipolla, "Assessment of cardiotoxicity with cardiac biomarkers in cancer patients," Herz, vol. 36, no. 4, pp. 325-332, 2011.

[7] A. Colombo, C. A. Meroni, C. M. Cipolla, and D. Cardinale, "Managing cardiotoxicity of chemotherapy," Current Treatment Options in Cardiovascular Medicine, vol. 15, no. 4, pp. 410-424, 2013.

[8] V. B. Pai and M. C. Nahata, "Cardiotoxicity of chemotherapeutic agents: incidence, treatment and prevention," Drug Safety, vol. 22, no. 4, pp. 263-302, 2000.

[9] A. Iqubal, M. K. Iqubal, S. Sharma et al., "Molecular mechanism involved in cyclophosphamide-induced cardiotoxicity: old drug with a new vision," Life Sciences, vol. 218, pp. 112131, 2019.

[10] S. Kusumoto, H. Kawano, T. Hayashi et al., "Cyclophosphamide-induced cardiotoxicity with a prolonged clinical course diagnosed on an endomyocardial biopsy," Internal Medicine, vol. 52, no. 20, pp. 2311-2315, 2013.

[11] Y. Kanda, T. Matsumura, K. Maki, T. Matsuyama, S. Chiba, and H. Hirai, "Fatal cardiac toxicity in two patients receiving same-day administration of cyclophosphamide and cytarabine as conditioning for hematopoietic stem cell transplantation," Haematologica, vol. 86, no. 9, pp. 1002-1003, 2001.

[12] S. Ishida, N. Doki, N. Shingai et al., "The clinical features of fatal cyclophosphamide-induced cardiotoxicity in a conditioning regimen for allogeneic hematopoietic stem cell transplantation (allo-HSCT)," Annals of Hematology, vol. 95, no. 7, pp. 1145-1150, 2016.

[13] G. Alemayehu, "Ethnobotanical profile of Croton macrostachyus (Euphorbiaceae) in Ethiopia: review of the literature," International Journal of Research in Pharmacy and Pharmaceutical Sciences, vol. 3, no. 1, pp. 209-222, 2018.

[14] W. Arika, Y. Abdirahman, M. Mawia et al., "In vivo antidiabetic activity of the aqueous leaf extract of Croton macrostachyus in alloxan induced diabetic mice," Pharmaceutica Analytica Acta, vol. 6, no. 11, pp. 1-5, 2015.

[15] G. Romha, B. Admasu, T. Hiwot Gebrekidan, H. Aleme, and G. Gebru, "Antibacterial activities of five medicinal plants in Ethiopia against some human and animal pathogens," Evidence-Based Complementary and Alternative Medicine, vol. 2018, Article ID 2950758, 10 pages, 2018.

[16] A. Degu, E. Engidawork, and W. Shibeshi, "Evaluation of the anti-diarrheal activity of the leaf extract of Croton macrostachyus Hocsht. ex Del.(Euphorbiaceae) in mice model,"
BMC Complementary and Alternative Medicine, vol. 16, no. 1, p. 379, 2016.

[17] E. N. Bum, E. Ngah, R. N. Mune et al., "Decoctions of Bridelia micrantha and Croton macrostachyus may have anticonvulsant and sedative effects," Epilepsy \& Behavior, vol. 24, no. 3, pp. 319-323, 2012.

[18] T. B. Nguelefack, R. C. Dutra, A. F. Paszcuk, E. L. de Andrade, and J. B. Calixto, "TRPV1 channel inhibition contributes to the antinociceptive effects of Croton macrostachyus extract in mice," BMC Complementary and Alternative Medicine, vol. 15, no. 1, p. 293, 2015.

[19] A. Kamanyi, M. Mbiantcha, T. B. Nguelefack et al., "Antinociceptive and anti-inflammatory activities of extracts from the stem bark of Croton macrostachyus (Euphorbiaceae) in mice and rats," Journal of Complementary and Integrative Medicine, vol. 6, no. 1, pp. 1-17, 2009.

[20] T. G. Kiristos, Z. T. Mengesha, A. Kebede, and K. K. Chaithanya, "Phytochemical screening and evaluation of antibacterial activities of Croton macrostachyus stem bark extracts," Drug Invention Today, vol. 10, no. 1, pp. 2727-2733, 2018.

[21] OECD, OECD Guideline for Testing of Chemicals, Vol. 425, OECD, Paris, France, 2008.

[22] A. Braca, N. De Tommasi, L. Di Bari, C. Pizza, M. Politi, and I. Morelli, "Antioxidant principles from Bauhinia tarapotensis," Journal of Natural Products, vol. 64, no. 7, pp. 892-895, 2001.

[23] Y. Mythili, P. T. Sudharsan, and P. Varalakshmi, "dl- $\alpha$-lipoic acid ameliorates cyclophosphamide induced cardiac mitochondrial injury," Toxicology, vol. 215, no. 1-2, pp. 108-114, 2005b.

[24] A. H. Viswanatha Swamy, U. M. Patel, B. C. Koti, P. C. Gadad, N. L. Patel, and A. H. Thippeswamy, "Cardioprotective effect of Saraca indica against cyclophosphamide induced cardiotoxicity in rats: a biochemical, electrocardiographic and histopathological study," Indian Journal of Pharmacology, vol. 45, no. 1, pp. 44-48, 2013.

[25] K. A. Alhumaidha, D. O. Saleh, M. A. Abd El Fattah, W. I. ElEraky, and H. Moawad, "Cardiorenal protective effect of taurine against cyclophosphamide-induced toxicity in albino rats," Canadian Journal of Physiology and Pharmacology, vol. 94, no. 2, pp. 131-139, 2016.

[26] L. Bhatt, B. Sebastian, and V. Joshi, "Mangiferin protects rat myocardial tissue against cyclophosphamide induced cardiotoxicity," Journal of Ayurveda and Integrative Medicine, vol. 8, no. 2, pp. 62-67, 2017.

[27] O. R. Ogunsanwo, A. A. Oyagbemi, T. O. Omobowale, E. R. Asenuga, and A. B. Saba, "Biochemical and electrocardiographic studies on the beneficial effects of gallic acid in cyclophosphamide-induced cardiorenal dysfunction," Journal of Complementary and Integrative Medicine, vol. 14, no. 3, 2017.

[28] S. K. Bjelogrlic, J. Radic, V. Jovic, and S. Radulovic, "Activity of d,l-alpha-tocopherol (vitamin E) against cardiotoxicity induced by doxorubicin and doxorubicin with cyclophosphamide in mice," Basic Clinical Pharmacology Toxicology, vol. 97, no. 5, pp. 311-319, 2005.

[29] H. H. Mansour, S. M. El Kiki, and H. F. Hasan, "Protective effect of $\mathrm{N}$-acetylcysteine on cyclophosphamide-induced cardiotoxicity in rats," Environmental Toxicology and Pharmacology, vol. 40, no. 2, pp. 417-422, 2015.

[30] N. Sinha and P. K. Dabla, "Oxidative stress and antioxidants in hypertension-a current review," Current Hypertension Reviews, vol. 11, no. 2, pp. 132-142, 2015. 
[31] A. B. Shori, "Screening of antidiabetic and antioxidant activities of medicinal plants," Journal of Integrative Medicine, vol. 13, no. 5, pp. 297-305, 2015.

[32] E. J. Garcia, T. L. C. Oldoni, S. M. Alencar, A. Reis, A. D. Loguercio, and R. H. M. Grande, "Antioxidant activity by DPPH assay of potential solutions to be applied on bleached teeth," Brazilian Dental Journal, vol. 23, no. 1, pp. 22-27, 2012.

[33] L. Bi, X. Tian, F. Dou, L. Hong, H. Tang, and S. Wang, "New antioxidant and antiglycation active triterpenoid saponins from the root bark of Aralia taibaiensis," Fitoterapia, vol. 83, no. 1, pp. 234-240, 2012.

[34] M. Carocho and I. C. Ferreira, "A review on antioxidants, prooxidants and related controversy: natural and synthetic compounds, screening and analysis methodologies and future perspectives," Food and Chemical Toxicology, vol. 51, pp. 15-25, 2013.

[35] K. W. Chan, N. M. Khong, S. Iqbal, and M. Ismail, "Isolation and antioxidative properties of phenolics-saponins rich fraction from defatted rice bran," Journal of Cereal Science, vol. 57, no. 3, pp. 480-485, 2013.

[36] C. Y. Cheok, H. A. K. Salman, and R. Sulaiman, "Extraction and quantification of saponins: a review," Food Research International, vol. 59, pp. 16-40, 2014.

[37] J. Grassmann, “Terpenoids as plant antioxidants," Vitamins \& Hormones, vol. 72, pp. 505-535, 2005.

[38] J. Grassmann, S. Hippeli, and E. F. Elstner, "Plant's defence and its benefits for animals and medicine: role of phenolics and terpenoids in avoiding oxygen stress," Plant Physiology and Biochemistry, vol. 40, no. 6-8, pp. 471-478, 2002.

[39] P. O’Brien, C. Carrasco-Pozo, and H. Speisky, "Boldine and its antioxidant or health-promoting properties," Chemico-Biological Interactions, vol. 159, no. 1, pp. 1-17, 2006.

[40] A. G. Samaranayaka and E. C. Li-Chan, "Food-derived peptidic antioxidants: a review of their production, assessment, and potential applications," Journal of Functional Foods, vol. 3, no. 4, pp. 229-254, 2011.

[41] X. Duan, W. Zhang, X. Li, and B. Wang, "Evaluation of antioxidant property of extract and fractions obtained from a red alga, Polysiphonia urceolata," Food Chemistry, vol. 95, no. 1, pp. 37-43, 2006.

[42] A. Elzaawely and S. Tawata, "Antioxidant activity of phenolic rich fraction obtained from Convolvulus arvensis L. leaves grown in Egypt," Asian Journal of Crop Science, vol. 1, no. 4, pp. 32-40, 2012.

[43] S. Vats, "Antioxidant activity of callus culture of Vigna unguiculata (L.) walp," Researcher, vol. 4, no. 6, pp. 22-24, 2012.

[44] M. Park and M. Kim, "Analysis of antioxidant and anti-inflammatory activities of solvent fractions from Rhynchosia nulubilis cultivated with Ganoderma lucidum mycelium," Preventive Nutrition and Food Science, vol. 22, no. 4, pp. 365-371, 2017.

[45] D. Bridges, "Weight loss effects of methotrexate and cyclophosphamide," Oncotarget, vol. 8, no. 3, p. 14569, 2017.

[46] M. A. Khan, "Immune potentiating and antitoxic effects of camel milk against cyclophosphamide-induced toxicity in BALB/C mice," International Journal of Health Sciences, vol. 11, no. 4, pp. 18-22, 2017.

[47] J. Wong, L. T. Tran, K. A. Lynch, and L. J. Wood, "Dexamethasone exacerbates cytotoxic chemotherapy induced lethargy and weight loss in female tumor free mice," Cancer Biology \& Therapy, vol. 19, no. 1, pp. 87-96, 2018.
[48] J. G. Omole, O. A. Ayoka, Q. K. Alabi et al., "Protective effect of kolaviron on cyclophosphamide-induced cardiac toxicity in rats," Journal of Evidence-Based Integrative Medicine, vol. 23, pp. 1-11, 2018.

[49] P. T. Sudharsan, Y. Mythili, V. Sudhahar, and P. Varalakshmi, "Role of lupeol and its ester on cyclophosphamide-induced hyperlipidaemic cardiomyopathy in rats," Journal of Pharmacy and Pharmacology, vol. 57, no. 11, pp. 1437-1444, 2005 b.

[50] M. Chakraborty, J. V. Kamath, and A. Bhattacharjee, "Pharmacodynamic interaction of green tea extract with hydrochlorothiazide against cyclophosphamide-induced myocardial damage," Toxicology International, vol. 21, no. 2, pp. 196-202, 2014.

[51] P. T. Sudharsan, Y. Mythili, E. Selvakumar, and P. Varalakshmi, "Cardioprotective effect of pentacyclic triterpene, lupeol and its ester on cyclophosphamide-induced oxidative stress," Human \& Experimental Toxicology, vol. 24, no. 6, pp. 313-318, 2005a.

[52] M. N. Nagi, O. A. Al-Shabanah, M. M. Hafez, and M. M. Sayed-Ahmed, "Thymoquinone supplementation attenuates cyclophosphamide-induced cardiotoxicity in rats," Journal of Biochemical and Molecular Toxicology, vol. 25, no. 3, pp. 135-142, 2011.

[53] D. S. El-Agamy, M. A. Elkablawy, and H. M. Abo-Haded, "Modulation of cyclophosphamide-induced cardiotoxicity by methyl palmitate," Cancer Chemotherapy and Pharmacology, vol. 79, no. 2, pp. 399-409, 2017.

[54] M. Nandave, S. Ojha, and D. Arya, "Protective role of flavonoids in cardiovascular diseases," Natural Product Radiance, vol. 4, no. 3, pp. 166-176, 2005.

[55] L. Testai, A. Martelli, M. Cristofaro, M. C. Breschi, and V. Calderone, "Cardioprotective effects of different flavonoids against myocardial ischaemia/reperfusion injury in Langendorff-perfused rat hearts," Journal of Pharmacy and Pharmacology, vol. 65, no. 5, pp. 750-756, 2013.

[56] H. R. Vasanthi, N. ShriShriMal, and D. K. Das, "Phytochemicals from plants to combat cardiovascular disease," Current Medicinal Chemistry, vol. 19, no. 14, pp. 2242-2251, 2012.

[57] R. Ojha, J. Singh, A. Ojha, H. Singh, S. Sharma, and K. Nepali, "An updated patent review: xanthine oxidase inhibitors for the treatment of hyperuricemia and gout (2011-2015)," Expert Opinion on Therapeutic Patents, vol. 27, no. 3, pp. 311-345, 2017.

[58] G. Sahgal, S. Ramanathan, S. Sasidharan, M. N. Mordi, S. Ismail, and S. M. Mansor, "In vitro antioxidant and xanthine oxidase inhibitory activities of methanolic Swietenia mahagoni seed extracts," Molecules, vol. 14, no. 11, pp. 4476-4485, 2009.

[59] N. Wu, Y. Zu, Y. Fu et al., "Antioxidant activities and xanthine oxidase inhibitory effects of extracts and main polyphenolic compounds obtained from Geranium sibiricum L," Journal of Agricultural and Food Chemistry, vol. 58, no. 8, pp. 47374743, 2010.

[60] M. D. Santi, M. P. Zunini, B. Vera et al., "Xanthine oxidase inhibitory activity of natural and hemisynthetic flavonoids from Gardenia oudiepe (Rubiaceae) in vitro and molecular docking studies," European Journal of Medicinal Chemistry, vol. 143, pp. 577-582, 2018.

[61] E. Fachriyah, M. Ghifari, and K. Anam, "Isolation, Identification, and Xanthine oxidase inhibition activity of alkaloid compound from Peperomia pellucida," IOP Conference Series: Materials Science and Engineering, vol. 349, pp. 12-17, 2018. 
[62] P. Vikrama Chakravarthi, S. Murugesan, A. Arivuchelvan, K. Sukumar, A. Arulmozhi, and A. Jagadeeswaran, "In vitro xanthine oxidase inhibitory activity of Piper betle and Phyllanthus niruri," Journal of Pharmacognosy and Phytochemistry, vol. 7, no. 5, pp. 959-961, 2018.

[63] S. Nafees, S. Rashid, N. Ali, S. K. Hasan, and S. Sultana, "Rutin ameliorates cyclophosphamide induced oxidative stress and inflammation in Wistar rats: role of NF $\kappa \mathrm{B} / \mathrm{MAPK}$ pathway," Chemico-Biological Interactions, vol. 231, pp. 98-107, 2015.

[64] G. Cocco, P. Jerie, P. Amiet, and S. Pandolfi, "Inflammation in heart failure: known knowns and unknown unknowns," Expert Opinion on Pharmacotherapy, vol. 18, no. 12, pp. 1225-1233, 2017.

[65] L. Gesquière, N. Loreau, A. Minnich, J. Davignon, and D. Blache, "Oxidative stress leads to cholesterol accumulation in vascular smooth muscle cells," Free Radical Biology and Medicine, vol. 27, no. 1-2, pp. 134-145, 1999.

[66] Y. Mythili, P. T. Sudharsan, V. Sudhahar, and P. Varalakshmi, "Protective effect of d,l-alpha-lipoic acid on cyclophosphamide induced hyperlipidemic cardiomyopathy," European Journal of Pharmacology, vol. 543, no. 1-3, pp. 92-96, 2006. 